\title{
THE QUESTION OF DIACHYLON OINTMENT
}

DOUGLASS W. MONTGOMERY, M.D.

AND

GEORGE D. CULVER, M.D.

SAN FRANCISCO

A questionnaire recently sent out by a committee on the revision of the Pharmacopeia stirred up the difficult question of diachylon ointment. We answered by saying that we did not employ it, which was technically true, but like answers to most formal questions, was not the exact truth. We employ, and much to our advantage, various substitutes made with lead plaster. One of the first of these, introduced into dermatologic practice by Piffard, is made by melting together lead plaster and petrolatum.

The original diachylon ointment is difficult to prepare, while the foregoing requires some care but no particular skill to produce a smooth, odorless salve. The smell of the original diachylon ointment was something to remember.

One evening in Philadelphia the question of a dermatologist having an exclusive druggist arose, and was objected to on obvious grounds. The late Louis A. Duhring, however, flung in the remark: "Who makes your diachylon ointment?" There was no doubt of Duhring's ability as a therapeutist, and there was no question in his mind of the efficacy of diachylon ointment when correctly prepared. There was also no question in Hebra's mind of the utility of this preparation; and here arises an interesting speculation. It is now known that there are four kinds or isotopes of lead, three of which are radio-active, and all four having different atomic weights. ${ }^{1}$ I have often thought that possibly Hebra had his ointment made with radio-active lead, which would not be surprising, especially if the metal came from Bohemia.

Lead is heavy, bland, soft, smooth and unctious, and its compounds tend to partake of the nature of the simple element. It has another peculiarity; in traces, certain metals, such as lead and copper, pass into what seem to be colloidal hydroids by mere contact with water, conferring toxic properties to the water. This is known as oligodynamic action. ${ }^{2}$ The bland quality of lead and its compounds and the property of being toxic in traces possibly explain its favorable action in streptodermas, which primarily, or as superinfections, consti-

1. Richards, T. W., and Wadsworth, Charles: Atomic Weight of Lead of Radio-Active Origin, J. Am. Chem. Soc., December, 1916, p. 2613.

2. Bayliss, William: Principles of General Physiology, 1915, p. 108. 
tute the daily routine of a dermatologist's work. In infections on an irritable skin, it is necessary to have not only an antiseptic, but also a bland emollient dressing, and this the lead preparation affords.

The choice of the lead plaster to make the ointment is important, most of them are unfit for use. Some of them contain too much glycerin, and Engman showed us that this defect may be remedied by first breaking the lead plaster into small pieces, and gently heating them over a slow fire. Before Bolshevik madness struck Russia, we got an excellent lead plaster, especially prepared for making the ointment, from a firm in Petrograd.

Since the days of Hebra and Duhring, many advances have been made in the therapy of the conditions in which diachylon ointment was employed. In weeping eczema, diachylon ointment may heat and macerate the skin, and on this account many men employ, not an ointment, but a paste that will soak up the secretions. Ehrmann, for instance, recommended a boric acid ointment with a great capacity for absorbing water, which is due to the large amount of boric acid (more than 16 per cent.), to the presence of glycerin, which is hygroscopic, and to hydrous wool fat:

$\mathbf{R}$ Boric Acid ............................... gm.

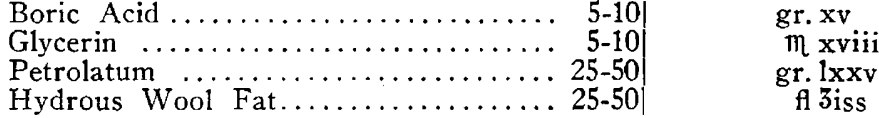

In making this ointment the boric acid powder should be mixed first with the hot glycerin to destroy the crystals, which otherwise irritate severely.

Often we prescribe modified lead plaster ointment composed of lead plaster and olive oil for irritable, desquamative affections of the lip with cracking. We usually make this ointment very dense, so that it will cling to the lip and we combine it with salicylic acid:

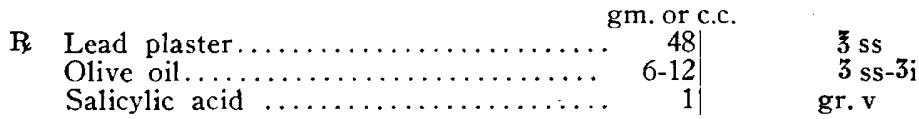

Melt the lead plaster and olive oil together over a slow fire, stirring constantly, and then add the salicylic acid.

In order to get an even distribution of the salicylic acid, it is best to mix it first with a very little hot castor oil. When the ointment is made with a very little olive oil, it is too firm to spread at ordinary room temperature, but it may be heated and then spread on a stout piece of cotton cloth and adapted to the lip. When made with 2 drams of olive oil to 1 ounce of lead plaster, the ointment has a good, tough consistency, and yet at ordinary house temperature is sufficiently pliable. This way of employing salicylated lead plaster in these rebellious lip affections we first learned in Isador Neumann's clinic. 
Much has been written of the ordinary ulcer of the leg, regarding it as a simple disease. It is rather a remarkable complex of diseases or etiologies eventuating in one lesion. Venous stasis, old age, scar tissue, malnutrition (in itself due to a multiplicity of causes) and wounds all give rise to a tissue with a low resistance to infection, and because of the watery condition of the tissues in inflammations of this region, there occurs an infection with streptococci, of all pathologic bacteria the most water loving. An irritating antiseptic, however, because of the weakness and irritability of the tissues, will increase the moisture and do more harm than good. A bland, heavy lead ointment often acts admirably, and the dressing of our choice is a lead plaster ointment with the addition of 2 per cent. of compound solution of cresol. In order to relieve the watery condition of the tissues, a well applied flannelet bandage is also necessary, for with a flood of water the heavy lead ointment may macerate and weaken the tissues still further. The compound solution of cresol, which mixes so well with the ointment, is mildly antiseptic, and also seems to aid by controlling pain and pruritus.

This ointment, however, in this situation may cause intolerable discomfort, and may either have to be temporarily discontinued or entirely abandoned. As before remarked, the etiology of ulcer of the leg is by no means simple, and in one case one factor will come to the fore and another in another.

Radium and roentgen-ray ulcers are now regarded by some as streptococcic infections on weakened tissue, and recently we have had two instances in which this form of lead ointment has acted admirably. In one of them a number of ointments had been previously employed unsatisfactorily; in the other, the patient, a physician, had employed orthoform powder for a long time, and finally it dawned on him that this drug, which quieted his pain so pleasingly, was in fact causing necrosis of the granulations. A change to this compound solution of cresol-lead ointment was followed by an immediate improvement in the appearance of the ulcer, and rapid healing. ${ }^{3}$

3. Louis Brocq was, we think, the first to call attention to the extensive eruption caused by orthoform, and William Dubreuill to the local necrosis. 